\title{
The End of Life, An Euthanasia Law
}

\section{Nunez Cubero $\mathrm{MP}^{1,2 *}$}

${ }^{1}$ Department of Bioethics, Comillas Pontifical University University, Spain

${ }^{2}$ Department of Philosophy, Ramon Llull University, Spain

*Corresponding author: M Pilar Núñez Cubero, Department of Bioethics, Comillas Pontifical University \& Department of Philosophy, Ramon Llull University, Spain, Email: pnunezcubero@ gmail.com

\section{Investigation Paper}

Since the First Euthanasia Bill was presented in our Parliament (2017), we had considered that this debate fell within the reflection that every plural and secular society should address, since it is not the debate itself, but the decisions that which may or may not be ethical. What should concern us is the inversion of the value system that has been introduced into our society and that conditions decisions. Technology has prolonged life, but it has also lengthened, at times, the process of dying with suffering for the patient and family. When a cure is not possible, and treatments become futile..., the duty to care for our patients, to relieve them and accompany them in the final trance persists.

Today, the law passed has placed the right to life and the right to death at the same ethical level and they are not comparable. "The law, the Constitution is due to absolute respect for human life". Dignity is inherent to the human being and does not lose it when life seems to be extinguished, and the person deteriorates. There is no "worthy death" is a person who dies and with all their dignity, the person is worthy "per se". Better to talk about death in peace.

We must reflect: "any law that decides an action without the possibility of correction, or of a possible change, scares me, and they are not trustworthy" (Axel Kahn) to die, to convert the right into the "obligation" to die.

\section{Today's Society Facing the End of Life}

Euthanasia is in the Hippocratic Oath: "I will never give anyone mortal medicine, no matter how much they ask me, nor will I take any initiative of this type. On the contrary, I will live and practice my art in a holy and pure way". The Codes of Medical Deontology have always included this type of conduct, and Euthanasia was a chapter of the Course of
Medical Deontology, later called Medical Ethics.

What could be accepted as an exception has become a right. How did we get here?. Biotechnology has prolonged life in quantity, sometimes incompatible with a "quality of life". You live to be 80, 90, 100 years old. Under what conditions? Do we have to do "everything" that science and technology offer today? The professionals were trained to do everything in their power ... because "while there is life there is hope." The family and even the patient himself asked that everything be done for his health.

At the same time, there have been important changes in the life of society that have led to the Welfare Society. A relevant value is given, a "Supervaluation" to everything young, beautiful, strong, a situation that has been called by Woody Allen as "the Culture of Triumph", so that there is no room for the sick, the elderly, the dying man. Death has disappeared from our daily and family environment. Talking about death today is Taboo, we avoid thinking about it and at the same time there has been a secularization of society that cannot give an ultimate explanation about death. Vulnerability is not accepted, and on the other hand, the patient is recognized as having personal autonomy over an excess of technology, which is sometimes wanted and sometimes feared.

Technology has made immortality appear to be achieved, and in the meantime, some have their bodies preserved by cryogenization while waiting for the treatment for the process that led to their death to be discovered. Others, the so-called "transhumanist" philosophers, assure that life will be prolonged, hundreds of years, and that even a "posthuman" man will be able to achieve immortality.

At present, it is found that sophisticated and high-tech medicine is cold and not very human. It is estimated that $80 \%$ 
of patients die outside the home in Hospitals or Residences, which leads to dying alone, in an artificial setting, among indifferent people, outside the usual environment. And the question arises: is technician and sophisticated medicine more humanizing?. Should that entire science and technology offer today be done? Because it is not the same to help the one who is living than to prevent the one who is dying from dying. There have been cases of authentic therapeutic ferocity, what today we call Therapeutic Obstinacy, which have led to what the law expresses when it writes: "the debate on euthanasia is periodically revived, as a result of personal cases that move public opinion (BOGC, page 2). A time has come when the End of life has sparked a debate at various levels: scientific, philosophical, social, ethical (moral) and legal.

\section{Scientific Debate}

This debate refers to the criteria of death, the process of death and the persistent vegetative state. Taking into account the scientific dimension, there has been a paradigm shift, the cause of death is no longer only due to cardiorespiratory arrest, or what today we call death in asystole or stopped heart. For years, brain death has been incorrectly spoken of, which should be called brain death, because in order for death to be affirmed, in these cases, not only does the brain lose its activity, but the brain stem must do it at the same time, the better call it brainstem, while the heart and respiration are still maintained in "life support" devices, when the patient is already, brain dead.

Death in these cases is certified after proceeding to assessment tests, which mark when life support must be removed (disconnect the patient). This situation has allowed the removal of organs for transplantation. However, it must be pointed out that there is an essential difference between brain death and the persistent vegetative state, since in the latter PVS, the functions of the brain stem remain active, maintaining vegetative life and therefore the patient is alive, in brain death, better encephalic death the patient has ceased to have all his functions and is therefore dead, even though he is still connected to a respirator.

Death cannot be considered as an act or a final moment, but rather a process that will have to be followed, and in which the patient can still decide. Not in vain did Hans Jonas affirm in the year 2000 that "We keep a scientific ignorance regarding the exact point that separates life and death".

\section{Philosophical Debate}

The assessment that today is made of human perfection, and of the requirements that define the person, has raised a question, can you stop being a person at some point in your life? Some affirmations of modern utilitarian or autonomist philosophers maintain that there are "Humans non persons", those who have lost or have not come to have cognitive abilities, and "Persons non humans", attributing this category to some primates.

On the other hand, the quality of life is related to the dignity of the person, and dignified death, raising the debate on dignity.

We can define the quality of life, such as Independence for the needs of daily life, with a capacity for the life of Relationship expressed in hours of social life with family, health personnel, friends, and with the control of Pain and other Symptoms (insomnia, appetite, constipation ...). Professionals today have a therapeutic arsenal, not only to prolong life, but to control pain and other symptoms.

The concept of dignity is not an extrinsic concept of "appearances", but an intrinsic concept. "Dignity is based on being, and because it has dignity it deserves respect, and for the mere fact of being a person, of having a specific essence, it must be respected and treated in a qualitatively different way. The dignity of people lies in their BEING and not in their WORKING (F. Torralba)".

Thus, talking about a dignified death does not make sense. Dignity is inherent to the human being. Every human being has dignity and death accompanies that dignity. All death is worthy. The Congregation for the Doctrine of the Faith, in its Letter Samaritanus Bonus on the care of people in the critical and terminal phases of life, dated September 22, 2020, affirms that "the so-called "dignified death" is rejected because it is based on a utilitarian anthropological conception, it conditions life to well-being, beauty, the delight of physical life and ignores the spiritual dimensions of existence... Human Life has value in itself". For the philosopher Immanuel Kant, in his last stage, the philosophical idea of human dignity is fundamental. In this sense, Kant affirms, "man is an end in himself, not a means for the uses of other individuals, the existence of people is an absolute value and, therefore, they are worthy of all moral respect. Human beings have value and not price and Adela Cortina comments in her Minimal Ethics: "Everyone must treat himself and others, never simply as a means, but always as an end in himself. However, what constitutes the only condition under which he can something being an end in itself, does not simply have a relative value, that is, a price, but an intrinsic value: dignity".

\section{Social Debate}

The social debate is in the street. Some groups in society ask to end one's life. The concept of "do not suffer" has been introduced as a slogan "do not suffer". 
Legislators have echoed and tried to respond: "The law tries to collect these wishes and give a legal, systematic balanced and guarantee response to a sustained DEMAND of today's society, such as euthanasia... (BOCG page 1)... and it is the legislator's obligation to attend to the demands and VALUES of society, preserving and respecting their rights (BOCG page 2)".

The first bill presented in 2017, refers to a percentage of $77.5 \%$ of individuals in favor of this law without disclosing the representation of the groups surveyed.

The cinema has allowed us to see images of this type of performance such as movies: Mar Adentro; The Barbarian Invasions; Million dollar Baby; The English Patient.

\section{Ethical Debate}

Behaviors of this type raise a series of questions, about facts, values and duties. Is the human being the owner of his life, or a simple administrator of it? Can a person end his life or that of another person? Obviously he has the physical power to do so, but should he? Is it moral? Is it ethical?.

One of the four principles of Bioethics is the principle of autonomy, according to which the person is considered an autonomous, moral and responsible agent and as such has to be incorporated into decision-making in everything that concerns him. These four principles are also arranged hierarchically, with the first level being the principles of dignity and justice and the second level being those of beneficence and autonomy. It is evident that the exercise of autonomy is not comparable to the exercise of protection of life. The autonomy requires life to be able to exercise.

\section{Ethical Issues at the End of Life Arise}

- Between 1965 to 1982 when science and technology raised whether the new treatments did not produce a futile prolongation of life and the decisions of "not starting" or "withdrawing a treatment" were weighed (Cases of Baby Doe and Karen Quinlan, among others)

- From 1983 to 2000 the debate on euthanasia began, while reflecting on the therapeutic fierceness or the possibility of letting die

- In 2000, people began to speak of "dignified" death, given the deterioration that chronic and degenerative diseases can cause

- In 2002, the term "due care" was introduced.

If we take into account the care dimension

- Disease had always led to Natural Death, but
- $\quad$ Starting in 1970 , people began to speak of Controlled Death in the United States, when people wanted to say something about their dying process and Advance Directives or Advance Wills were introduced.

- In 1980 there is talk of Preventive Death at the same time that the Pro-Euthanasia legal movement begins; death is preferred before the possibility of prolonging life due to Therapeutic Obstinacy.

- Already in 1990 Palliative Death was introduced, in which palliative sedation must be clearly distinguished from terminal sedation.

Palliative care is slowly being introduced in Continental Europe, following the inauguration in 1967 of the Hospice movement by Cycely Saunders in the UK, to assist terminally ill patients with the aim of "dying, living"; "You matter because you are you, until the last moment of your life".

Almost contemporary Elisabeth Kübler-Ross, a doctor completely dedicated since 1969 to the care of terminally ill patients, traveled the United States teaching the care of patients at the end of life, and assuring: "The way we treat sick men in their last years days reflects the degree of mental and spiritual evolution that we have reached in our culture".

Until the 1960s, when faced with an incurable patient and with great pain or suffering, painkillers and sedatives could be administered, even when these medications accelerated death, once the patient had settled his affairs with God, the Sacraments if his religious faith he asked for it, and to have signed his obligations with the family and society before a notary, if necessary. In these cases the principle of double effect applied: seek positive action, and simply tolerate negative.

From the Vatican, Pope Pius XII, in 1957 made reference to the subject of resuscitation and the treatment of pain including morphine. The Pope knew how to raise, with the concepts of his time, the question of abstaining or withdrawing from a certain treatment, although, in many cases, the death of the patient was followed more quickly. And when doctors complained of feeling deprived of treatments for the intense chronic pain of some processes at the end of life, and they were reluctant to morphine, Pope Pius XII recommended the use of such narcotics, when a serious medical indication was given.

Thus, the field of Euthanasia is openly entered, creating an authentic paradigm of semantic confusion, with its nuances of: active, omission, passive, direct, indirect, voluntary, nonvoluntary, and involuntary. 


\section{EUTANASIA}

Paradigma de la confusión semántica

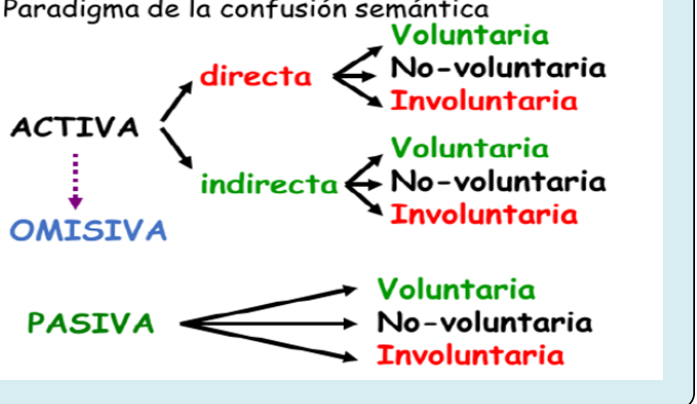

Today Euthanasia has been defined as "The action or omission that, by its nature or intention, causes death in order to eliminate any pain" (Congregation for the Doctrine of the Faith, May 5, 1980). Later they have followed other definitions of euthanasia very similar to it, such as the definition of the Dutch Euthanasia Law, or that of the Spanish Penal Code of 2010, which add "at the request of the patient himself". The new law of our country defines it as "the deliberate act of ending the life of a person, produced by the express will of the person himself and in order to avoid suffering ... In our bioethical and criminal doctrines there is today a wide agreement to limit the use of "euthanasia" to that which occurs actively and directly "(BOCG. Pag.2). The law does not consider omission a form of euthanasia.

The elements that constituted euthanasia contemplated the Intention (also the Omission) to cause the death of a person, with an irreversible or incurable disease, capable by itself of causing death in a short time, in order to eliminate suffering already request of the person himself. (The new law has introduced some modifications that are collected more ahead). The motivation for such a decision is based on the patient's part in:

- An intolerable suffering for which its liberation is requested and

- The autonomy to judge and decide on the conditions in which they want to live.

On the part of the doctor

- Compassion and duty to do what is best for the patient and

- Respect for the patient's autonomy.

"Compassion, says the Letter Samaritanus Bonus of the Doctrine of the Faith, (September 22, 2020), does not consist in precipitating or causing the death of our neighbor, but rather that we are called to welcome the sick and support them in the midst of difficulties, and to be able to offer affection, attention, protection and means to alleviate suffering... Life is a gift that has been given to us".

It is necessary to clearly define what euthanasia is not: not starting or interrupting treatment when the patient requests it in a serious, explicit, repeated and voluntary way is not. Neither is it not to initiate or interrupt a treatment when its beginning or continuation does not make sense according to medical criteria; as well as starting pain treatment, even though it may hasten death. In order not to incite euthanasia, it is necessary to fight against therapeutic Obstinacy (formerly fierceness), which is defined as the prolongation of the dying process through treatments that have no other meaning than to prolong the biological life of the patient. If before the means were weighed as ordinary and extraordinary or, proportionate and disproportionate, now they are defined as mandatory means and optional means.

In this fight against therapeutic obstinacy, the concept of "Limitation of therapeutic effort" LET has been introduced, better defined today as "Adequacy of treatment", and which consists of the end of efforts to fight death, in one case specifically, and restrict, limit or not initiate life support measures, CPR cardiopulmonary resuscitation, in short, it is about not entering into therapeutic obstinacy, being necessary to know or request consent and maintain palliative care.

The question is how to know when to limit or adapt a treatment, for which the concept of Futility will serve us. A treatment is futile if it does not improve the prognosis, symptoms, or recurrent diseases, it produces disproportionate benefits at a personal, family, or socioeconomic level. Futility can be quantitative, the degree of probability that a medical treatment will produce a result, and is said to be futile if it involves less than $1 \%$ of benefit to the patient. It is qualitative if it consists of a treatment that merely preserves a permanent state of unconsciousness or cannot end the dependence on intensive care.

Regarding Sedation at the end of life, it is a deep, induced and maintained sleep in which the difference in intention will have to be made well, if you seek to "not prolong" or "end" life. . Cicely Saunders, founder of the Hospice movement for the care of the terminally ill in the UK, writes "to treat or not to treat, but never the intention to procure death." Without forgetting that when healing is no longer possible, the duty of caring persists.

\section{Legall Debate}

The reasons for Eut in Asia has to be Euthanasia they are the Right to a dignified death, the right not to suffer and the right to decide on one's life.

Euthanasia and assisted suicide have always been in the Spanish Penal Code, although the penalties had been 
considerably reduced in the Penal Code of 2010. It did not make a difference between euthanasia or assisted suicide, it said: "Anyone who causes or I will actively cooperate with necessary and direct acts to the death of another, will be punished with penalties of. The debate was practically reduced to the Prior Instructions. The person could express by written personally or by a legal representative, the treatments or the rejection of the same I wish they were taken into account if the moment came, he could not express himself. The document does not It was in no case a limiting factor for conducts, and it established as a limit that the situation was not the predicted one and doubted what the patient would like in that case that his wish to be against the legal system or against the lex artis". Today it fits in these Instructions to proceed with euthanasia.

Some jurists have shown eskeptical about the value of these instructions, as it is very different to write in full state of health what you want and what you will want when the weight of the disease has altered the patient's lucidity and forces The first proposal of the current Spanish law dates from January 30, 2017 and states: It is widely agreed that the purpose of medicine in the Twenty First century has two objectives of the same category and importance. Prevent and cure ill ages and help people to die in peace citizens, through the development of a palliative medicine that relieves its citizens, through the development of a palliative medicine that alleviates their suffering and respects their feelings and their decisions.

It should be remembered that the editors are that The Goals of Medicine", published by Daniel Callahan and Mark J. Hanson at the Hasting Center in 1996, point out as 4 the goals of medicine:

- Disease prevention and health promotion;

- Heal the sick and care for the chronically ill;

- Rehabilitation of injuries and sequelae and relief of suffering;

- Avoid premature death and ensure a peaceful death. Preventing premature death means not anticipating death due to an unnecessary intervention such as euthanasia action, "being alive until death" as Paul Ricoeur said at 90 in 2003.

Ensure a peaceful death, without therapeutic obstinacy that prolongs the dying process.

The new law (December 17, 2020) opens its first page stating that, "this law aims to provide a legal, systematic, balanced and guarantee response to a sustained demand from today's society such as euthanasia." In his first project he gave survey results. Where, when and to whom was the survey directed?.
The law affirms: "the legalization and regulation of euthanasia are based on the compatibility of some essential principles that are the foundation of people's rights and, which are thus set forth in the Spanish Constitution. They are, on the one hand, the fundamental rights to life and physical and moral integrity, and on the other, constitutionally protected goods, such as dignity, freedom or the autonomy of the will. (BOCG, page 2). What difference does the law make between fundamental rights and property?. These rights and goods are not comparable because they are based on Values of different levels: life, a fundamental value and the autonomy of the will, secondary value because it requires life that is the basis of all rights. "Everyone has the right to life, this right to life does not exist based on a right, but on a fact of nature" (Bioethics Committee of Spain) and the law follows: "It seeks to respect the autonomy and will to end life, in a situation of serious and incurable disease, or of a serious, chronic and incapacitating disease, suffering unbearable suffering, which cannot be alleviated in conditions that it considers acceptable. To that end, this law regulates and decriminalizes euthanasia (BOCG, page 2)".

"When a fully capable and free person faces a vital situation that, in his opinion, violates his dignity and integrity, as defined in the Euthanasian context described above, the good of life may decline in favor of the other assets and rights with which it must be weighed, since there is no constitutional duty to impose or protect life at all costs and against the will of the holder of the right to life. For this same reason, the State is obliged to provide a legal regime that establishes the necessary guarantees and legal security (BOCG, page 3)". Life is the highest good that a person has to be able to exercise his values and rights, without it he can do nothing, but it is not an absolute good and he can sacrifice himself to save others or give his life for his Faith.

"Any person of legal age, in full capacity to act and decide, may request and receive such help, provided that they do so autonomously, consciously and informed, and that they are in the event of a serious and incurable disease or a serious chronic disease and disabling, causing intolerable physical or psychological suffering (BOCG, page 3)".

The dimensions of chronic and disabling disease or psychic suffering can be interpreted as a large door, open to euthanasia, as we have so often interpreted about the abortion law in which the mother's mental illness allowed abortion without age limits gestational, which was to have an abortion law on demand.

The law distinguishes between two different euthanasia behaviors:

- The direct administration of a substance to the patient by the competent healthcare professional and 
- The prescription or supply by the healthcare professional of a substance, so that it can be self-administered, to cause his own death (BOCG, page 4). This second modality known as assisted suicide, has been more typical of the United States and related countries that are governed by a liberal philosophy, according to which, a person can dispose of his life, but no one can dispose of the life of another. Warren Reich, founding member of the Kennedy Institute of Bioethics at Georgetown University in Washington, has responded to this argument that "doctor-patient trust is based on the reasoning that care never includes assisted suicide."

"At the same time, through the possibility of Conscientious Objection, legal certainty and respect for the freedom of conscience of the health personnel called to collaborate is guaranteed ... the professional can refuse and so shall record and inform his patient. However, the applicants' rights to euthanasia have to be covered".

It is legitimate to state that, if the State gives a right, it is its function to provide the means so that one can benefit from it, without imposing this right, as a duty, on doctors. The freedom of one ends where the freedom of the other begins. The Conscientious Objection must be real, without marking the professional objectors. "Health personnel do not kill," says the Bioethics Committee of Spain. And Axel Kahn, geneticist and member of the Committee National d'Ethique de France, bronze agnostic, as he defines himself, writes: "I distrust irreversible human actions." It is not possible to go back once euthanasia has been applied.

\section{Alternative to Euthanasia, a Peaceful Death}

The term dying in peace seems more appropriate than that of a dignified death, since, as every person is worthy, his death is also worthy. To die in peace is: to die surrounded by the affection of your loved ones, eliminating pain and suffering, to die a natural death, without unnecessary actions, with the necessary medical assistance and spiritual support if desired, understanding that not all people want religious help , but yes that each person, of whatever color or trend, has within them a capacity for transcendence and needs, at times, to express their feelings of guilt, rejection, rebellion and for this, they need someone who knows how to listen .
Letting die in peace, calls for the development of palliative care, support for terminally ill patients, the rejection of therapeutic obstinacy, and medical care, which demands their situation. The patient at the end of his life is in a state of maximum vulnerability, with physical pain; mentally discouraged in the face of deterioration and weakness due to the disease; social by feeling separated from their own and responsible for their suffering; Spiritual, the images and events of life, blurred, pass through his imagination many times. The family also experiences physical pain, due to work overload; psychic because death is still a rupture; social because caring for your patient limits other activities and relationships; spiritual guilt at times and remorse for not doing what would be necessary.

\section{Palliative Care}

To palliate temporarily means to give a well-being, to control the pain and the symptoms that accompany serious illnesses, especially in their terminal phase, (vomiting, and alterations of the intestinal or urinary rhythm, insomnia...). It also supposes emotional and social help because good communication is the center of all good care, offering spiritual care if desired and trying not to over-medicalize palliative care, but rather to offer a humane environment that makes the patient live until his death.

The sick at those times, have a certain fear and fear of the unknown where they walk, they appreciate the company, which is nothing more than taking into account the quality of life, comprehensive care, which helps them to live with an unlimited disease that will take them even a death in peace.

Accompanying is sitting in silence and convincing them that they deserve our attention. It is the welcoming gesture, the tender word, the respectful gaze, the closeness, an attitude of candlelight towards and with the patient. It is to show him that he has value for us because as Paul Ramsey (one of the pioneers of Bioethics) affirms: "There is nobility and dignity in assisting the dying" And I quote Lèvinas, the French philosopher who affirms that the face of the other he asks, when he writes: "Before death there is always one last chance, and if you die for lack of meaning. We are all responsible."

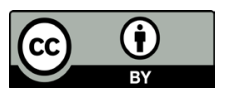

